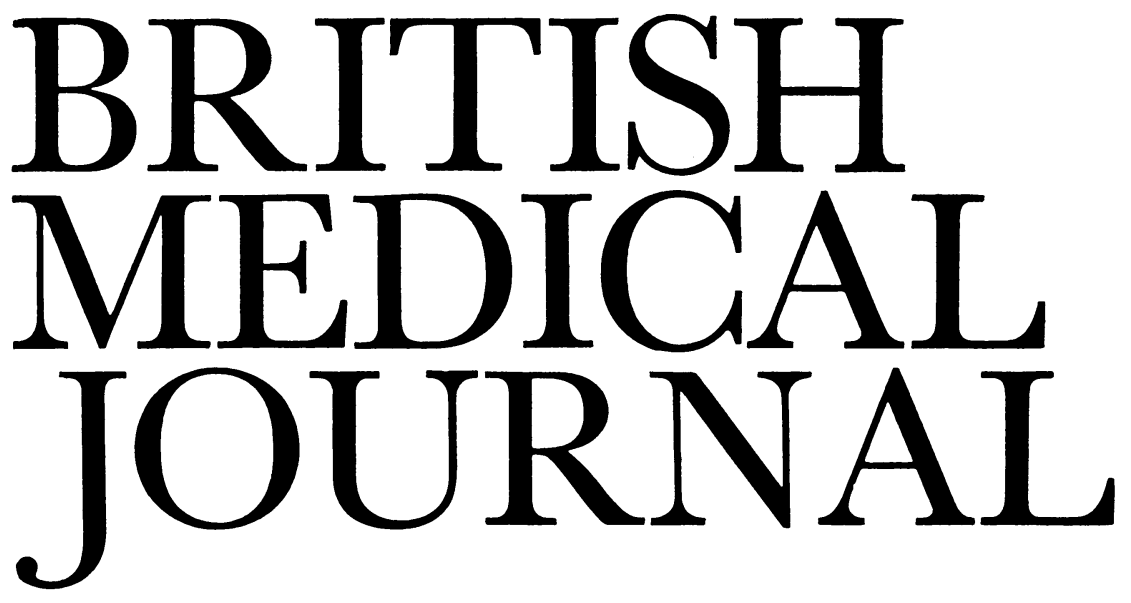

LONDON, SATURDAY 9 MAY 1981

\title{
Antacids for duodenal ulcer
}

At present antacids seem to play two principal parts in the treatment of ulcers. They have a secure place in relieving the pain of duodenal ulcer and a not-so-definite contribution to the healing of ulcers. Neither of these actions is as straightforward as might at first appear.

The many recent accounts of trials of new drugs in duodenal ulcers almost invariably include a proviso that the patients were given "emergency" supplies of antacids to be taken if they suffered ulcer pain during the trial. Clearly most of the physicians who undertake such trials share the belief of most patients that antacids really do relieve ulcer pain. Yet reports have recently appeared that when the matter has been examined scientifically relief of pain with antacid is no better than with a placebo. ${ }^{1}$ This unsatisfactory state of affairs reflects the extraordinary fact that we do not know what causes ulcer pain. On endoscopic examination active ulcers may often be found in patients who suffer no pain at all, while patients who do complain of pain may have no hole in their duodenal mucosa. Furthermore, ulcer pain cannot be produced by perfusing acid through the ulcerated duodenum. ${ }^{2}$ Since we do not know the cause of ulcer-induced pain we do not know how antacids relieve pain-whether by a "direct-contact" effect $^{3}$ or indirectly, by reducing intragastric and therefore intraduodenal acidity. We have, therefore, no well-based guidelines for the best use of antacids, except that pain must be relieved and that there must be no adverse reactions to the treatment.

When a patient has a mild symptomatic relapse, using antacids to relieve the ulcer pain usually presents no problem. The occasional, intermittent, and short-term administration of antacids rarely gives rise to side effects. In these circumstances the choice of an antacid preparation is governed by acceptability and convenience. No one antacid is palatable to every patient, ${ }^{4}$ and each must identify the one that he tolerates best. In practice most patients prefer to carry antacids as tablets rather than as a liquid. For a patient to chew a few antacid tablets a day for a few days during a mild ulcer relapse is safe and satisfactory and therefore quite acceptable medically. Nevertheless, we do not know whether intermittent treatment with antacids is better than, or even as good as, similar intermittent (demand) treatment with a drug such as cimetidine, since the matter has not been studied thoroughly.

When symptoms are more severe and prolonged, the healing of the ulcer needs to be speeded up, because healed ulcers usually do not hurt and do not give rise to acute complications. Antacids are claimed to be able to heal ulcers in addition to relieving symptoms. ${ }^{5}$ Nevertheless, a generally assumed prerequisite for the healing of ulcers is that intragastric acidity should be neutralised-and in patients with duodenal ulcer, who usually secrete large amounts of acid, that means using very large amounts of liquid antacids ${ }^{6} 7$ (tablets of antacid are not as good at neutralising acid as liquid formulations $^{8}$ ). Liquid antacids are not all equally powerful, and cost-benefit analyses of the antacids available in different countries $^{4} 910$ have shown that antacid preparations have as much as a 10-fold range of "potency" (capacity to mop up acid) and an almost 40 -fold range in the cost of the recommended course of treatment.

Should antacids be used to heal ulcers? More than 20 drugs or groups of drugs have now been shown to increase the rate of healing of duodenal ulcers, so that if antacids are to be used for this purpose their superiority over these other forms of treatment must be established. Given that antacids can heal ulcers, how does this form of treatment compare with others for safety, cost, compliance by the patients, and in the likelihood that healing will be followed by recurrence? Recent studies have shown that the cost of giving sufficiently large amounts of antacid to heal ulcers is similar to the cost of a course of cimetidine, ${ }^{11}$ and the probability of recurrence is similar after healing an ulcer with antacids and with cimetidine. ${ }^{12}$ These results imply that there is little to choose between antacids and cimetidine. Even so, the very large amounts of antacid which must be taken frequently-and for a month or more-are often unacceptable to patients, so that compliance may become a problem. Moreover, high dosage or long-continued treatment with antacids may be associated with side effects and may even produce dangerous iatrogenic disease.

In part, the side effects of treatment with antacids depend on the chemical composition of the mixture. Aluminium hydroxide, for example, is converted to aluminium phosphate in the intestine and may cause a phosphate-deficiency syndrome with anorexia, muscular weakness, and osteomalacia. ${ }^{13}$ Hypophosphataemia may develop as early as two weeks after starting treatment. ${ }^{14}$ Aluminium-containing antacids increase urinary and faecal excretion of calcium as well as decrease absorption 
of fluoride, with resulting skeletal demineralisation..$^{13}$ Aluminium is absorbed from the intestine, so that aluminiumcontaining antacids are potentially dangerous in patients with chronic renal failure with their risk of aluminium encephalopathy. ${ }^{15}$ Magnesium-containing antacids produce diarrhoea, and over half the patients given "healing" doses of antacids suffer from this symptom. Magnesium is also readily absorbed and in patients with renal failure may give rise to bradycardia. ${ }^{16}$ Calcium-containing antacids must not be used in view of the danger of renal damage caused by alkalosis and the hypercalcaemia resulting from absorption of calcium. ${ }^{17}$ Bismuth-containing antacids, which have been used for many years, particularly in France, have achieved notoriety there because adverse effects, including encephalopathy and arthropathy, have occurred even with "insoluble" bismuth salts. ${ }^{18} 19$

Some complications occur irrespective of the composition of the antacid preparation. For example, most antacid mixtures contain sodium ${ }^{20}$ and the intake of sodium may exceed minimal adult requirements by a factor of 20 . This high content of sodium may be distinctly dangerous for patients with associated sodium-retaining diseases. Antacids may predispose to infection by enteric pathogens as a result of removal of the barrier which gastric acid normally provides against alimentary infection, ${ }^{21}$ and travellers to the tropics have been advised to avoid antacids.

More important, antacids alter drug kinetics ${ }^{22}$ by affecting the absorption or excretion of other drugs. Absorption is altered by delayed gastric emptying and by binding of the drug in the intestine, while the alkalosis produced by antacids may affect the excretion of other drugs in urine. Drugs whose absorption is altered include antibiotics, digoxin, anticonvulsants, warfarin, and anti-inflammatory drugs. The antacidinduced increase in urinary $\mathrm{pH}$ results in the more rapid excretion of salicylates and, conversely, the retention in the body of basic drugs such as quinidine.

This is an impressive list of potential adverse effects of treatment with large amounts of antacids. Thus, set against their lack of clear advantages over specific ulcer-healing drugs, antacids cannot be recommended for the healing of duodenal ulcers.

1 Sturdevant RAL, Isenberg JI, Secrist D, Ansfield J. Antacid and placebo produced similar pain relief in duodenal ulcer patients. Gastroenterology $1977 ; 72: 1-5$.

${ }^{2}$ Harrison A, Hagie L, Schapira M, Isenberg JI. Gastroduodenal acidification failed to induce pain consistently in patients with active symptomatic duodenal ulcer. Gastroenterology 1979;76:1152.

${ }^{3}$ Guerre J, Pergola F, Wegmann R. Etude histo-enzymatique de l'effet du phosphate d'aluminium sur la muqueuse gastrique. 12 malades. Nouv Presse Med 1980;9:3525-9.

4 Jones B, Rhodes M, Rhodes J. Which antacid ? An assessment of liquid antacids. Practitioner 1977;219:559-62.

5 Peterson WL, Sturdevant RAL, Frankl HD, et al. Healing of duodenal ulcer with an antacid regimen. $N$ Englf Med 1977;297:341-5.

6 Malagelada J-R, Carlson GL. Antacid therapy. Scand $\mathcal{f}$ Gastroenterol $1979 ; 14$, suppl $55: 67-76$.

7 Grossman MI. The use of antacids in the treatment of peptic ulcer. Scand f Gastroenterol 1980;15, suppl 58:37-40.

8 Singh A, Mital HC. Comparative assessment of antacid preparations. Pharm Acta Helv 1977;52:319-23.

${ }^{9}$ Güller R. Pufferkapazität und Kosten der flüssigen Antazida 1977. Schweiz Med Wochenschr 1977;107:807-10.

${ }^{10}$ Dutro MP, Amerson AB. Comparison of liquid antacids. $N$ Engl $\mathcal{F ~} \mathrm{Med}$ $1980 ; 302: 967$

11 Finkelstein W, Isselbacher KJ. Comparative costs of cimetidine and antacids. N Englf Med 1979;300:370.

12 Center for Ulcer Research and Education. Is duodenal ulcer recurrence more common after cimetidine treatment? Gastroenterology 1980;78: 1152 .

13 Spencer $\mathrm{H}$, Lender $\mathrm{M}$. Adverse effects of aluminium-containing antacids on mineral metabolism. Gastroenterology 1979;76:603-6.
14 Shields HM. Rapid fall of serum phosphorus secondary to antacid therapy. Gastroenterology 1978;75:1137-41.

15 Arieff AI, Cooper JD, Armstrong D, Lazarowitz VC. Dementia, renal Wo failure, and brain aluminium. Ann Intern Med 1979;90:741-7.

16 Berns AS, Kollmeyer KR. Magnesium-induced bradycardia. Ann Intern Med 1976;85:760-1.

17 Robson RH, Heading RC. Obsolete but dangerous antacid preparations. Postgrad Med f 1978;54:36-7.

${ }_{18}$ Martin-Bouyer G, Barin C, Beugnet A, Cordier J, Guerbois H. Intoxications par les sels de bismuth administrés par voie orale. Gastroenterol Clin Biol 1978;2:349-56.

19 Serfontein WJ, Mekel R. Bismuth toxicity in man. II. Review of bismuth blood and urine levels in patients after administration of therapeutic bismuth formulations in relation to the problem of bismuth toxicity in man. Res Commun Chem Pathol Pharmacol 1979;26:391-411.

20 Yokel RA. Sodium and potassium levels in antacids. Am $\mathcal{F}$ Hosp Pharm $1977 ; 34: 200-2$.

21 Anonymous. Antacids and brucellosis. $\mathrm{Br} \mathrm{Med} \mathcal{F}$ 1978;i:739-40

22 Hurwitz A. Antacid therapy and drug kinetics. Clin Pharmacokinet 1977; 2:269-80.

\section{Ethnic factors in disease}

The study of ethnic differences in patterns of disease has often spilled over into the political and philosophical arena, stifling or objective investigation and rational discussion. In Britain $\vec{A}$ political attitudes may lead to our missing the opportunity for 0 research among the two ethnic minority groups, the West 9 Indians and immigrants from the Indian subcontinent, who 0 have arrived in large numbers in the last 20 years. The patterns of disease are different in these races, but whether these differences are due to genetic or environmental factors is not $\stackrel{\&}{\infty}$ clear. Longitudinal studies, even crossing more than one generation, might provide answers. Few such investigationsor even remotely related projects-are in progress, nor do they appear to be supported by the major research institutions.

Earlier this month ethnic patterns of disease were discussed $\frac{0}{D}$ by clinicians and epidemiologists in Birmingham (and a full $\stackrel{2}{\Rightarrow}$ report will be published in the Postgraduate Medical fournal). Much of the epidemiological research has relied on death certificates and regional health authority Hospital Activity Analysis returns, work which will not be easily repeated in a few years' time. Identification of immigrants is at present made on the response to the question about place of birth, but over half of young blacks aged 20-25 years admitted to hospital in 1979 were born in Britain. Furthermore, Hospital Activity Analysis returns are frequently not completed in this respect, andlike death certificates and census forms-they do not record 9 ethnic origins.

Professor H G Langford (Jackson, Mississippi,) and Professor P S Sever (London) agreed that the incidence of hypertension in urban blacks was higher than in whites, but the reason remained unknown. Genetic factors as shown in twin studies contrasted with differences in environment such as diet 0 and sodium intake; each seemed to have some bearing. $K_{0}$ Woods (Birmingham) showed that red cell $\mathrm{Na} / \mathrm{K}$ pump activity was reduced in white normotensives compared with white hypertensives, whereas no such differences could be shown between black normotensives and hypertensives. G Beevers (Birmingham) confirmed that, in spite of the increased frequency of hypertension, blacks in Britain have a lower incidence of coronary artery disease than do whites but a higher rate of cerebrovascular disease and strokes. Other known risk factors, such as smoking, plasma lipid concentrations, and obesity, do not seem to be responsible. 